\title{
Antibiotic knowledge and self-care for acute respiratory tract infections in Mexico
}

\author{
Ralph Gonzales, MD, MSPH, (') Alma Ethelia López-Caudana, MD, MSc, DrSc, (2) Tulia González-Flores, BSN, ${ }^{(3)}$ \\ Janaki Jayanthan, $\mathrm{MPH},{ }^{(4)}$ Kitty K Corbett, $\mathrm{PhD}, \mathrm{MPH},{ }^{(4)}$ Hortensia Reyes-Morales, MD, MSc, DrSc. ${ }^{(5)}$
}

\section{Gonzales R, López-Caudana AE, González-Flores T, Jayanthan J, Corbett KK, Reyes-Morales H. Antibiotic knowledge and self-care for acute respiratory tract infections in Mexico .} Salud Publica Mex 20I2;54:I52-I57.

\begin{abstract}
Objective. To examine knowledge of and self-treatment with antibiotics among medically-insured adults in Mexico. Materials and methods. We conducted a cross-sectional, interviewer-administered survey among $\mathrm{IO} I$ adult patients seeking care for acute respiratory tract infections in a family medicine clinic in Mexico. Knowledge scores were calculated as a composite of correct, incorrect and don't know responses. Factors associated with antibiotic knowledge and antibiotic self-treatment were explored with bivariate analyses. Results. $47 \%$ of participants were taking antibiotics prior to the visit, $20 \%$ were self-treating. Antibiotic knowledge was highly variable. Many participants believed common nonantibiotic treatments for colds and coughs were antibiotics, such as ambroxol (45\%), Desenfriol $(45 \%)$ and paracetamol (44\%). Older participants ( $>40$ years) had better knowledge scores. Discussion. Self-treatment with and misperceptions about antibiotics are common among medically insured adults seeking medical attention in Mexico.
\end{abstract}

Key words: Antibiotics; respiratory tract infections; selfcare; Mexico
Gonzales R, López-Caudana AE, González-Flores T, Jayanthan J, Corbett KK, Reyes-Morales H. Conocimiento y automedicación de antibióticos para infecciones respiratorias en México. Salud Publica Mex 2012;54:152-157.

\section{Resumen}

Objetivo. Examinar el conocimiento y automedicación de antibióticos en adultos asegurados en México. Material y métodos. Llevamos a cabo un estudio transversal mediante la administración de un cuestionario a $\mathrm{IOI}$ pacientes adultos que solicitaban atención médica por infección respiratoria aguda en una clínica de medicina familiar en México. La puntuación de conocimiento estuvo compuesta por respuestas correctas, incorrectas y "no sé", los factores asociados con conocimiento y automedicación de antibióticos fueron explorados mediante análisis bivariado. Resultados. $47 \%$ de los participantes tomaron antibióticos previamente y $20 \%$ fueron automedicados. La puntuación de conocimiento fue muy variable. Muchos de los participantes creyeron que tratamientos comunes para resfriado y tos eran antibióticos, como ambroxol (45\%), Desenfriol (45\%) y paracetamol (44\%). Los participantes con mayor edad (>40 años) obtuvieron mejores puntuaciones de conocimiento. Discusión. Las percepciones erróneas sobre antibióticos y su automedicación son comunes en adultos que buscan atención médica en México.

Palabras clave: antibióticos; infecciones respiratorias; autocuidado; México

(I) University of California. San Francisco, California, EUA.

(2) Instituto Mexicano del Seguro Social. Cuernavaca, Morelos, México

(3) Universidad de Guanajuato. Guanajuato, México

(4) Simon Fraser University. Burnaby, BC, Canada.

(5) Instituto Nacional de Salud Pública. Cuernavaca, Morelos, México.

Received on: June 2, 201I • Accepted on: February 15, 2012

Corresponding author: Ralph Gonzales. University of California.

3333 California Street, Box I2 II, San Francisco, CA 94I I8, EUA.

E-mail: ralphg@medicine.ucsf.edu 
C ommunity-acquired infections caused by antibioticresistant microbes are a major and growing threat to global public health. To help reduce the rate of antibioticresistant bacterial infections, there is an urgent need to curb excess antibiotic use. ${ }^{1-5}$ Acute respiratory tract infections (ARIs) account for a large share of community antibiotic use in many countries, ${ }^{6-8}$ although frequently the antibiotics prescribed for ARIs are unnecessary. ${ }^{9}$ In response, national and international campaigns are promoting judicious antibiotic use, particularly for ARIs. ${ }^{10-12}$

Multifaceted educational strategies have shown promise in reducing unnecessary antibiotic use, but their effectiveness may vary across different populations. ${ }^{13-18}$ One subgroup of particular concern consists of persons who use antibiotics without a prescription -such as leftover antibiotics or antibiotics purchased in the community. Studies have highlighted a common practice of self-treatment of ARIs with antibiotics in Mexico, among immigrant Latino populations living in the US and in other countries. ${ }^{7,19-22}$ Self treatment with antibiotics is a concern not only because the antibiotics are frequently unnecessary, but also because patients may take these antibiotics sporadically (which breeds resistance), and -in cases when they actually need antibiotics- they may be taking the wrong antibiotic. Access to doctors and prescription medications is likely to be a key factor related to self-medication with antibiotics, although other social and cultural factors have been implicated as well..$^{22-24}$

To control for lack of access to health care as a confounding factor among patients who self-treat with antibiotics, we conducted a study among primary care patients with health insurance who were seeking medical attention for ARIs in a Mexican integrated health care delivery system. In this study, we examined knowledge, attitudes and behavior related to antibiotic use for ARIs, and specifically examined the relationship between antibiotic knowledge and self-treatment with antibiotics.

\section{Materials and methods}

An interviewer-administered patient survey was conducted in July and August 2009 at the Family Medicine Clinic in the Mexican Institute of Social Security (IMSS - Instituto Mexicano del Seguro Social) in Cuernavaca, Morelos, Mexico. The IMSS is a combined employer, State and worker sponsored, integrated health care delivery system that provides care to roughly $40 \%$ of the Mexican population. Being the main health system in Mexico, it provides services to formally employed workers and their families.
The study population consisted of a convenience sample of patients with ARIs over 13 years of age who were seeking medical attention for their illness. Potential participants (patients seeking care for ARIs) were identified by clinic staff and referred to study personnel for explanation of the study. Eligible patients were selected through consecutive sampling among those who fulfilled inclusion criteria.

The study was approved by the institutional review boards (Ethics and Research) of IMSS, the National Institute of Public Health, Mexico, the University of California, San Francisco, and Simon Fraser University, Canada.

The survey instrument consisted of 24 questions (a combination of 45 closed and open-ended items) related to age, sex, education, children in household, illness features, health care seeking behaviors, self-care (including antibiotic use), and knowledge about antibiotics. The instrument was refined following pilot testing with 25 clinic patients. After obtaining verbal informed consent from participants or parents for those less than 18 years of age, study personnel administered the survey instrument and documented all patient responses verbatim. Each survey took approximately 10 to 5 minutes to administer.

We restricted our analysis to patients presenting with upper ARI symptoms (nasal discharge, nasal obstruction, sneezing, sore throat, cough, and ear pain), headache, malaise or fever, of $\leq 21$ day. Exploratory analyses were performed on key variables to assess the distribution of responses. We created an overall summary score for accurate antibiotic knowledge related to which medications are and are not antibiotics (see list in Table II). Participants received a score of +1 for correct identification of the medication, a score of -1 for incorrect identification, and a score of 0 if they answered "don't know". The list included four true antibiotics, and eight non-antibiotics. Thus, maximum and minimum scores were $\pm 12, \pm 8$ and \pm 4 for all medications, non-antibiotic medications and antibiotic medications, respectively. Antibiotic knowledge scores were compared between groups of age, sex, and prior antibiotic use by using unpaired t-test, and across different strata of education level, and self-treatment using ANOVA. All analyses were performed using SAS version 9.s (Cary, North Carolina).

\section{Results}

One-hundred one patients fulfilled inclusion criteria and completed interviews. Study population characteristics are shown in table I. The average age of participants was 41 years, two-thirds were female and a minority $(39 \%)$ 
Table I

STUDY POPULATION CHARACTERISTICS, Cuernavaca, Mexico, July - August 2009

\begin{tabular}{lc}
$\quad(n=101)$ & Percent \\
$\begin{array}{l}\text { Age, years } \\
13-19\end{array}$ & 6 \\
\hline $20-29$ & 23 \\
\hline $30-39$ & 20 \\
\hline $40-49$ & 20 \\
\hline $50-59$ & 20 \\
\hline$>60$ & 11 \\
$\begin{array}{l}\text { Gender }(n=100) \\
\text { Female }\end{array}$ \\
\hline Male & 67 \\
\hline
\end{tabular}

Education

\begin{tabular}{ll}
$<$ middle school & 61 \\
\hline High school & 13 \\
\hline$>$ college & 26
\end{tabular}

Illness duration, days mean (SD)

Illness symptoms

Sore throat

\begin{tabular}{ll} 
Cough & 67 \\
\hline Nasal congestion & 53 \\
\hline Headache & 36 \\
\hline Fever & 34 \\
\hline General malaise & 33 \\
\hline
\end{tabular}

Prior doctor visit 29

I Private practice $5(18)$

\begin{tabular}{lr}
2 Retail pharmacy & $3(\mathrm{II})$ \\
\hline 3 IMSS or ISSSTE* & $18(64)$ \\
\hline 4 Local health center & $2(7)$
\end{tabular}

* IMSS and ISSSTE (Institute of Security and Social Services for Governmental Employees) are the largest public health institutions for formal workers and their families in Mexico

‡ Belonging to Ministry of Health had received more than a middle school education; $30 \%$ were illiterate or having only elementary school. A variety of symptoms was present among participants, most commonly sore throat $(67 \%)$ and cough $(53 \%)$. Almost one-third reported a previous doctor visit for the present illness-the vast majority within the same delivery system.

Participants' knowledge about which medications are antibiotics is shown in table II. There was wide variation in accurate knowledge across a range of cough and cold medications, including medications that are not medically indicated for ARI management such as captopril (anti-hypertensive) and pravastatin (cholesterol lowering medication). Cold remedies commonly used in Mexico were frequently identified as antibiotics, such as ambroxol (45\%), Desenfriol (45\%) and paracetamol $(44 \%)$.

We found that participants scored across the entire spectrum of antibiotic knowledge scores (figure 1). Inaccurate knowledge was more common for non-antibiotics than for antibiotics, as shown by the distribution of scores less than zero. Over two-thirds (69\%) reported incorrectly that at least 1 of the non-antibiotic medications was an antibiotic, and almost half (48\%) identified 3 or more non-antibiotics incorrectly. In contrast, with regard to the four true antibiotics on the list, almost three-fourths of participants $(74 \%)$ correctly classified the four true antibiotics on the list (or stated they did not know); and only $23 \%$ incorrectly classified 1 true antibiotic as a non-antibiotic.

Overall knowledge scores were substantially lower among participants younger than 40 years of age compared with older adults, but did not vary significantly by sex or education level, although there is a trend for higher score among higher educated patients (table III). Knowledge scores also did not vary among persons using and not using antibiotics prior to the visit, nor among those self-treating with antibiotics (although sample sizes are quite small for these comparisons).

Approximately half $(47 \%)$ of our sample had taken antibiotics for the illness for which they were seeking

Table II

Antibiotic knowledge: “Which medications are antibiotics?” Cuernavaca, Mexico, July - August 2009

\begin{tabular}{|c|c|c|c|c|c|c|c|c|c|c|c|c|}
\hline \multirow[t]{2}{*}{ Answer } & \multicolumn{12}{|c|}{ Percentage } \\
\hline & Ampicilin & Ciprofloxacin & Erythromycin & Trimethoprim & Ambroxol & Aspirin & Captopril & Desenfriol* & Naproxen & Paracetamol & Pravastatin & Ranitidine \\
\hline Yes & 89 & 49 & 43 & 50 & 45 & 45 & 9 & 45 & 37 & 44 & 7 & 19 \\
\hline No & 5 & 8 & 10 & 7 & 45 & 50 & 47 & 46 & 50 & 53 & 25 & 56 \\
\hline Don't know & 6 & 43 & 47 & 44 & II & 5 & 44 & 9 & 14 & 4 & 68 & 25 \\
\hline
\end{tabular}

* Desenfriol is a commonly used treatment for colds in Mexico, and contains paracetamol, phenylephrine and chlorpheniramine.

Boldface indicates a significant result 


\section{Overall antibiotic knowledge score}

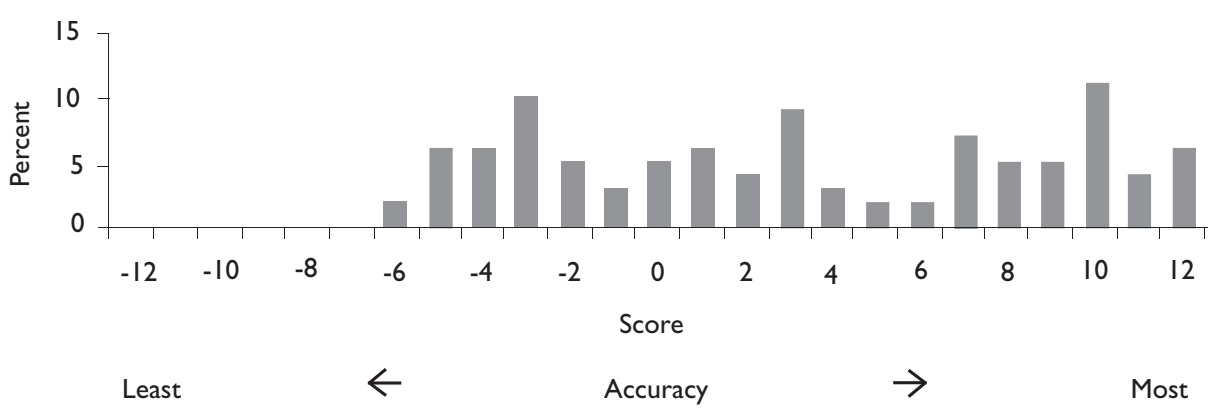

Non-antibiotic knowledge score

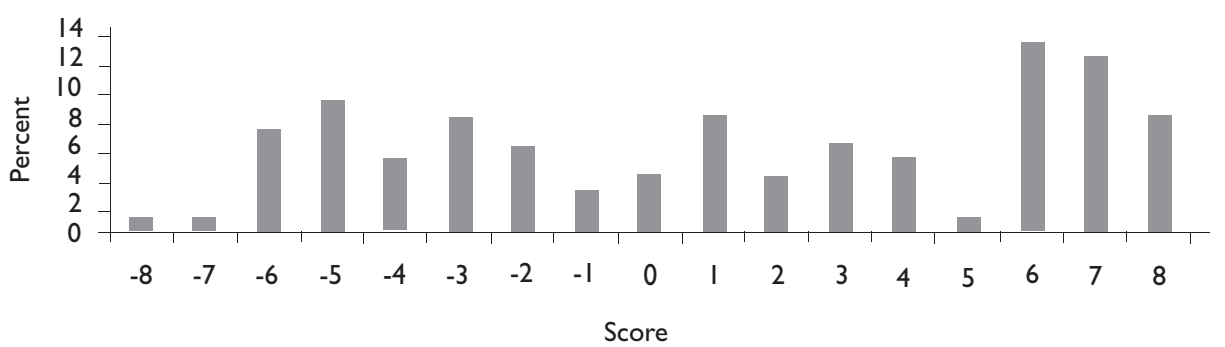

True antibiotic knowledge score

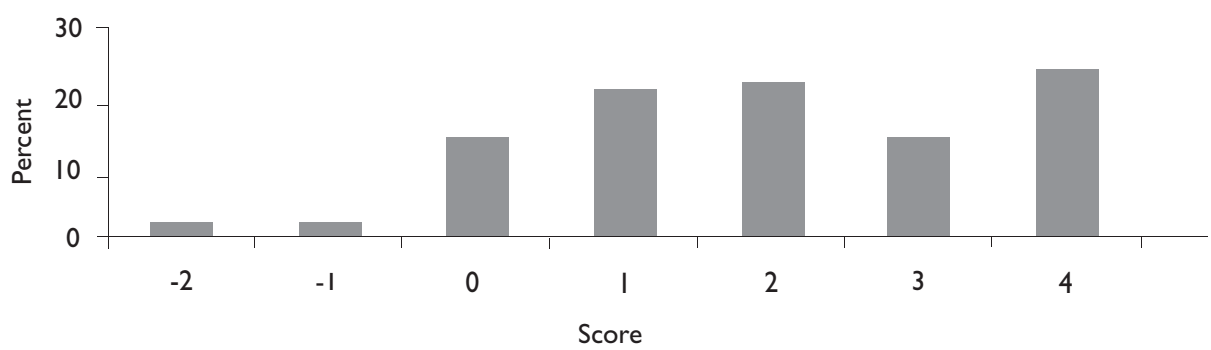

Figure I. Frequency distribution of overall (I 2 medications QUeried), non-Antibiotics (8 medications), and true ANTIBIOTIC (4 MEDICATIONS) KNOWLEDGE SCORES

care (data not shown). A doctor's recommendation accounted for only half of the antibiotics previously taken. Forty percent of participants taking antibiotics had initiated them on their own. In addition, a significant proportion of participants $(26 \%)$ reported using antibiotics that were not actually antibiotics.

\section{Discussion}

Approximately half of the medically-insured adults seeking medical attention for ARIs in our study in
Mexico was already receiving treatment with antibiotics prior to their doctor's visit, and forty percent of these patients were self-treating with antibiotics. This estimate is similar to studies with community-based samples. ${ }^{21,25}$ Various studies have remarked on longstanding practices of self-medication of the public with antibiotics, the ready availability of antibiotics often without a prescription, attitudes endorsing use of antibiotics for a wide range of illnesses, and patterns of over-prescription and inappropriate prescription in Mexico and among Latinos in the US. ${ }^{23 ;} 26-30$ In recent years, programs dedicated to 
Table III

ANTIBIOTIC KNOWLEDGE SCORES ACROSS SOCIODEMOGRAPHIC FACTORS AND ANTIBIOTIC USE behaviors. Cuernavaca, Mexico, July - August 2009

\begin{tabular}{lll} 
Age & Mean $(S D)$ & Pvalue* \\
$<40$ years & $1.10(5.64)$ & $<0.0001$ \\
\hline$>40$ years & $5.49(4.70)$ &
\end{tabular}

Sex

\begin{tabular}{lll} 
Female & $3.88(5.8 I)$ & 0.44 \\
\hline Male & $2.93(5.60)$ &
\end{tabular}

Education

\begin{tabular}{lll} 
< middle school & $2.65(5.42)$ & 0.31 \\
\hline High school & $3.15(6.72)$ & \\
\hline$>$ college & $4.65(5.5 I)$ &
\end{tabular}

Prior antibiotic use

\begin{tabular}{lll} 
Yes & $3.83(5.73)$ & 0.38 \\
\hline No & $2.85(5.49)$
\end{tabular}

Self-treatment with antibiotics

\begin{tabular}{lll} 
Yes $(n=20)$ & $4.70(5.40)$ & 0.35 \\
\hline No $(n=28)$ & $3.43(6.00)$ & \\
\hline Not using Abx $(n=53)$ & $2.57(5.50)$ \\
&
\end{tabular}

controlling antibiotic resistance by the World Health Organization and other international organizations (and formal, intersectoral declarations that highlight such concern) aim to improve the knowledge, attitudes, and practices that underlie inappropriate antibiotic use. ${ }^{31}$ Against that macro-level context, it is important to develop national and community-level programs, and to be effective, these should be based on understanding of current patterns of belief and use.

Our study found that the accuracy of the public's knowledge about which medications are antibiotics is particularly poor, particularly in the classification of non-antibiotic medications and symptomatic/combination cold remedies as antibiotics. The unreliability of self-reports of antibiotic consumption suggests that researchers should exercise caution in extrapolating from public reports of antibiotic use and consumption, and its pressure on development of antibiotic resistance.

Of the sociodemographic variables we could evaluate, only age was a significant predictor of antibiotic knowledge. Older participants (age $>40$ years) had much greater overall knowledge about which antibiotics were and were not antibiotics than younger participants.
This increased knowledge may be the result of greater lifetime experience with ARIs and medication management, since we do not see any significant correlation of education with antibiotic knowledge. The lack of association between antibiotic knowledge and prior antibiotic use or self-treatment with antibiotics also suggests that the factors that influence self-treatment with antibiotics are not driven by greater or lesser knowledge about which medications are antibiotics. This finding has interesting implications for the development of programs targeting consumers of these medications. It adds to the evidence that education-only programs that emphasize knowledge--such as the recent unsuccessful educational campaign in the US that was specifically designed to decrease self-treatment with antibiotics among Latinos- are not as effective as comprehensive, multi-faceted efforts. ${ }^{32}$

Our study's findings should be interpreted in light of its limitations. Our study population consisted of a convenience sample of patients, and may not fully reflect the broader population of adult Mexican primary care patients in IMSS. We also cannot be certain to what extent well-described research biases observed in Latino patients in US studies were also present in our study -such as simpatía (in which participants tend to give the socially desirable answer instead of the truth). If this were present, it is likely our study's estimate of self-treatment with antibiotics might have been even higher (for example, if patients over-reported how frequently the antibiotics they were taking were prescribed or recommended by a physician).

In conclusion, these findings suggest that antibiotic self-treatment of ARIs is common among medically insured primary care patients in Mexico. Educational efforts to promote appropriate antibiotic use, and to encourage antibiotic use only if a doctor prescribes it, will require broader-scaled strategies-such as education tailored to the community, directed at pharmacies, and addressing family influences on antibiotic self-treatment. Educational strategies will also need to ensure that the population understands which medications are actually antibiotics. Further studies are necessary for identifying antibiotic knowledge and self-treatment in other populations, such as those affiliated with different health institutions. In addition, it will be necessary to consider the new legislation recently established in Mexico that forbid the sale of antibiotics without medical prescription.

\section{Acknowledgments}

This study was funded in part by a Fulbright GarciaRobles All Disciplines award \#8584 (RG). 
Declaration of conflict of interests. The authors declare that they have no conflict of interests.

\section{References}

I. Gonzales R, Corbett KK, Wirtz V, Dreser A. Making a difference: quality improvement interventions for resistant infections in developing countries. BMJ 2008;336(7650):948-949.

2. Pan American Health Organization. Prevention and control of antimicrobial resistance in the Americas. Washington (DC): $\mathrm{PAHO} / \mathrm{HCP} /$ HCT/I39/99, 1999.

3. Levy SB. Confronting multidrug resistance. A role for each of us. JAMA 1993;269:1840-1842.

4. Wirtz VJ, Dreser A, Gonzales R. Trends in antibiotic utilization in eight Latin American Countries, 1997-2007. Rev Panam Salud Publica 2010;27:219-225

5. Van de Sande-Bruinsma N, Grundmann H, Verloo D, Tiemersma E, Monen J, Goossens H, et al. European Antimicrobial Resistance Surveillance System Group; European Surveillance of Antimicrobial Consumption Project Group. Antimicrobial drug use and resistance in Europe. Emerg Infect Dis 2008; I4:I722-1730.

6. Grijalva CG, Nuorti JP, Griffin MR. Antibiotic prescription rates for acute respiratory tract infections in US ambulatory settings. JAMA 2009; 19;302:758-766

7. Calva J, Bojalil R. Antibiotic use in a periurban community in Mexico: a household and drugstore survey. Soc Sci Med 1996;42: I I 2 I-I I 28.

8. Parimi N, Pinto-Pereira LM, Prabhakar P. Caregivers' practices, knowledge and beliefs of antibiotics in paediatric upper respiratory tract infections in Trinidad and Tobago: a cross-sectional study. BMC Fam Pract 2004;5:28.

9. Dreser A, Wirtz VJ, Corbett KK, Echániz G. Uso de antibióticos en México: revisión de problemas y políticas. Salud Publica Mex 2008; 50(4):480-487.

10. World Health Organization. Interventions and strategies to improve the use of antimicrobials in developing countries: a review. Geneva:WHO/CDS/CSDR/DRS/200I.9, 200I.

II. Coenen S, Ferech M, Haaijer-Ruskamp FM, Butler CC, Vander Stichele RH, Verheij TJM, et al. European Surveillance of Antimicrobial Consumption (ESAC): quality indicators for outpatient antibiotic use in Europe. Qual Saf Health Care 2007; 16:440-445.

12. Gonzales R, Bartlett JG, Besser RE, Hickner JM, Hoffman JR, Sande $M A$, et al. Principles of appropriate antibiotic use for treatment of acute respiratory tract infections in adults: background, specific aims, and methods. Ann Intern Med 200I;134:479-486.

13. Ranji SR, Steinman MA, Shojania KG, Gonzales R. Interventions to reduce unnecessary antibiotic prescribing: a systematic review and quantitative analysis. Med Care 2008;46:847-862.

14. Perz JF, Craig AS, Coffey CS, Jorgensen DM, Mitchel E, May S, et al. Changes in antibiotic prescribing for children after a community-wide campaign. JAMA 2002;287:3103-3109.

I5. Davis RL, Wright J, Chalmers F, Levenson L, Brown JC, Lozano P, et al. A cluster randomized clinical trial to improve prescribing patterns in ambulatory pediatrics. PLoS Clin Trials 2007;2:e25.
16. Pérez-Cuevas R, Muñoz $O$, Guiscafré $H$, Reyes $H$, Tomé $P$, Gutiérrez G. Patrones de Prescripcion Terapéutica en Infección Respiratoria Aguda y Diarrea Aguda en dos Instituciones de Salud (IMSS-SSA) IV. Características de la Prescripción Médica. Gac Med Mex 1992;128:531-542.

17. Reyes-Morales H, Flores-Hernández S, Tomé-Sandoval P, PérezCuevas R. A multifaceted education intervention for improving family physicians' case management. Fam Med 2009;4I (4):277-284.

I8. Flores S, Reyes H, Perez-Cuevas R. Influence of physician factors on the effectiveness of a continuing medical education intervention. Fam Med 2006;38:5II-5I7.

19. McKee D, Mills L, Mainous AG. Antibiotic use for the treatment of upper respiratory infections in a diverse community. J Fam Pract 1999;48:993-996.

20. Gartin M, Brewis AA, Shwartz NA. Nonprescription Antibiotic Therapy: Cultural Models on Both Sides of the Counter and Both Sides of the Border. Med Anthropol Q 2010;24:85-107.

21. Parimi N, Pinto Pereira LM, Prabhakar P. The general public's perceptions and use of antimicrobials in Trinidad and Tobago. Rev Panam Salud Publica 2002;12:1 - 18.

22. Avorn J, Solomon DH. Cultural and economic factors that (mis)shape antibiotic use: the nonpharmacologic basis of therapeutics. Ann Intern Med 2000; I33: I28-135.

23. Mainous AG 3rd, Diaz VA, Carnemolla M. Factors affecting Latino adults' use of antibiotics for self-medication. J Am Board Fam Med 2008;21:128-134.

24. Coffman MJ, Shobe MA, O'Connell B. Self-prescription practices in recent Latino immigrants. Public Health Nurs 2008;25:203-2II. 25. Mainous AG 3rd, Cheng AY, Garr RC, Tilley BC, Everett C], McKee MD. Nonprescribed antimicrobial drugs in Latino community, South Carolina. Emerg Infect Dis 2005; I I:883-888.

26. Mainous AG 3rd, Diaz VA, Carnemolla M. Factors affecting Latino adults' use of antibiotics for self-medication. J Am Board Fam Med 2008;2I:128-134.

27. Céspedes A, Larson E. Knowledge, attitudes, and practices regarding antibiotic use among Latinos in the United States: review and recommendations. Am J Infect Control 2006;34:495-502.

28. Corbett KK, Gonzales R, Leeman-Castillo BA, Flores E, Maselli J, Kafadar K. Appropriate antibiotic use: variation in knowledge and awareness by Hispanic ethnicity and language. Prev Med 2005;40:162-169. 29. Wirtz VJ, Reich MR, Leyva-Flores R, Dreser A. Medicines in Mexico, 1990-2004: Systematic review of research on access and use. Salud Publica Mex 2008;50 suppl 4:S470-S479.

30. Dreser A, Wirtz VJ, Corbett KK, Echániz G. Uso de antibióticos en México: revisión de problemas y políticas. Salud Publica Mex 2008;50 supl 4:S480-S487.

31. World Health Organization. Antimicrobial resistance. Fact sheet No. 194. [monografía en internet]. Geneve:WHO, $201 \mathrm{I}$ [consultado 2012 febrero I]. Disponible en: http://www.who.int/mediacentre/factsheets/ fs 194/en/.

32. Mainous AG 3rd, Diaz VA, Carnemolla M. A community intervention to decrease antibiotics used for self-medication among Latino adults. Ann Fam Med 2009;7:520-526. 